\title{
25
}

\section{Selection of assembly system configurations: A decision support system}

\author{
A. K. Kochhar \\ Department of Mechanical Engineering \\ UMIST, Manchester M60 1 QD, United Kingdom \\ Tel: +44-161-200-3801 Fax: +44-161-200-8721 \\ Email: mcjmscc@fs1.me.umist.ac.uk

\section{Y. T. Abdul-Hamid} \\ University of Bradford, Bradford, United Kingdom
}

\begin{abstract}
Design of competitive and effective manufacturing and assembly systems has to take account of a large number of technical, human and economic parameters. Frequently this information is not readily available to the system designers. This paper describes the systemization of knowledge relating to the large number of technical and human parameters which can affect the choice of automated dedicated and automated programmable assembly systems. Decision trees and production rules are used to link the different parameters. The structured knowledge, in the form of a prototype decision support system, has been validated using a number of case studies.
\end{abstract}

\section{Keywords}

Assembly system, Decision Trees, Manufacturing, Structured Knowledge

\section{INTRODUCTION}

The very highly competitive world-wide market environment is forcing many manufacturing companies to reorganise their manufacturing operations in order to eliminate inefficiencies and non value adding activities. Business process reengineering techniques are being used, amongst other things, for the simplification and redesign of manufacturing systems. An important aspect of redesign is the choice of the type of manufacturing system to be used. It is necessary to take careful account of all the related factors before deciding on the suitability of a particular type of manufacturing plant configuration in a given situation. The problem, which faces the decision maker, is the vast amount of information which 
should be taken into account when making the choice of manufacturing system configurations. It is not possible to find a single source covering the requirements for any one type of assembly system.

This paper describes the systematization of knowledge relating to the large number of parameters which can affect the choice of assembly systems. The systemized knowledge has been incorporated in a prototype decision support system. For illustration purposes two main types of assembly systems, namely automated dedicated, and automated programmable, are considered. The successful application of each type of assembly system requires the consideration of a number of technical and human factors.

\section{THE STRUCTURE OF THE KNOWLEDGE}

The knowledge has been structured in the form of two integrated decision trees:

1- Conditions for applying automatic assembly systems,

2- Conditions for applying programmable assembly systems.

These decision trees have been structured in the form of production rules. The main rule for each type consists of the main (or high level) conditions required to satisfy the goal, which is to assess the suitability of the successful implementation of a given type of assembly configuration in the environment under consideration. Each of the main conditions has its own sub-conditions, and sometimes sub-sub conditions. The objective of this systemization of knowledge, in the form of conditions and sub-conditions, is to simplify the process of assessing the areas on which attention should be focused.

\section{TECHNICAL AND HUMAN CONDITIONS OF DEDICATED AUTOMATIC ASSEMBLY SYSTEMS}

Dedicated automatic assembly systems are special design configurations, usually one of a kind. They may be partially constructed of standard components, but the total machine is unique to the product being assembled (Lynch 1976). The assembly cycle time in these systems is typically one to four seconds (Warnecke 1978). A dedicated assembly system should satisfy eight main conditions. Brief descriptions of the main conditions and their sub-conditions now follow.

\subsection{Design for assembly}

Design for assembly (DFA) is one of the most important conditions for the successful implementation of any assembly system, and it is particularly important in the automatic and programmable assembly systems. Nine sub-conditions are included here. The conditions related to the design of the product include: Minimization of the total number of separate parts in the product (Bailey 1986, Boothroyd et al 1982, Holbrook et al 1988); use of modular subassemblies for assembling the product, where each subassembly can be assembled, tested, and transferred separately (Boothroyd et al 1982, Holbrook et al 1988, Laszcz 1985, Riley 1983, Stoll 1986); the provision of a suitable base part or main body in the 
design of the product (Boothroyd et al 1982, Stoll 1986, Tipping 1969, Treer 1979); and, minimization of the number of assembly directions (preferably carrying out the assembly process out from the top direction only) (Boothroyd et al 1982, Holbrook et al 1988, Laszcz 1985, Stoll 1986, Tipping 1969, Treer 1979). The conditions related to the design of the individual parts include: designing the parts in such a way that they can be fed easily and reliably by the mechanical parts feeder and its attachments (Bailey 1986, Boothroyd et al 1982, Holbrook et al 1988, Laszcz 1985, Riley 1983, Stoll 1986, Tipping 1969, Treer 1979); designing the parts to be multi-functional, i.e. they can perform more than one function in the assembled product (Stoll 1986); designing the parts for multi-use, so that they can be used in many different products (Stoll 1986); the provision of compliance features, to facilitate the assembly of the parts (Bailey 1986, Boothroyd et al 1982, Holbrook et al 1988, Laszcz 1985, Stoll 1986, Treer 1979); and, designing the parts for ease of gripping by providing a large, flat, smooth top surface for vacuum or magnetic gripping, or by providing appropriate holes, slots, or tabs to aid grasping by mechanical grippers (Bailey 1986, Laszcz 1985, Stoll 1986).

\subsection{Automatic assembly workheads}

These devices carry out the required assembly task by placing and joining a part with the base part, or with other parts in the assembly. Three sub-conditions are included here to ensure the reliability and safety of the assembly system. These are: ensuring that jammed parts can be cleared quickly from the workheads, in order to avoid long delays in production (Tipping 1969, Wick et al 1987); the fail safe operation of workheads, i.e. should any failure occur, the workhead and machine or tooling must not be damaged (Tipping 1969, Wick et al 1987); and, ease of maintenance of the workheads, (Wick et al 1987).

\subsection{Parts presentation and feeding}

The third main condition is the provision of appropriate, efficient, and reliable equipment to feed and present the parts to the assembly workheads. The supply of parts in magazines is the most efficient and reliable method of presenting parts to the workheads. Hopper feeders are sometimes used for filling the magazines, but in many cases they are manually loaded. This manual intervention leads to higher assembly costs. Therefore, only one of the following reasons justifies using this method. These are: the parts are complex or very sensitive to be stored in bulk (Riley 1983, Wick et al 1987); the parts are very difficult to be fed down a mechanical parts feeder track individually (Riley 1983, Tipping 1969, Wick et al 1987); or, the parts can be purchased in magazines or strips forms (Treer 1979, Wick et al 1987). When the parts cannot be provided by magazines, then the second method is to feed them by mechanical parts feeders. Many conditions are required to implement this method successfully. These include: the selection of suitable feeders, which satisfy the requirements of the assembly system (Boothroyd et al 1982, Riley 1983, Tipping 1969, Treer 1979, Lotter 1989, Cokayne 1991, Aronson 1995); the selection of suitable discharge rails (tracks), which perform the functions of arranged storage and transfer of the parts from the feeder ((Boothroyd et al 1982, Tipping 1969, Lotter 1989, Cokayne 1991); the provision of a static removal point for the parts coming from the track, to enable the assembly workhead 
to pick the parts from the same point every time (Lotter 1989, Cokayne 1991); and, the provision of a separating device, to enable the assembly workhead to pick a single part each time (Wick et al 1987, Lotter 1989).

\subsection{Efficient control system}

An important condition in the operation of automatic assembly systems is the provision of an efficient control system. The main lower level conditions are: the ability to supervise all the necessary checking operations in the assembly system (The Institution of Production Engineers 1979, Wick et al 1987, Aronson 1995); the provision of a "count-and-stop" facility in the control system (Treer 1979); the provision of a memory system (Aronson 1995, Hollingum 1993); the provision of lockout features on assembly stations (Treer 1979, Butler 1993); the ability to control the movement of each assembly workhead (Treer 1979); the provision of indicator panels to display what is happening to the assembly machine (Aronson 1995, Butler 1993, Hollingum 1993); recording the assembly system performance, such as machine total cycles, good parts produced, and malfunctions at each station (Butler 1993, Hollingum 1993); and, the ability to interface with other controllers and computers (Treer 1979, Wick et al 1987, Butler 1993).

\subsection{Assembly system architecture}

The overall architecture of the assembly system has a significant impact on its day to day operation. A number of measures can be used to assess the quality and suitability of the architecture. This condition consists of several sub-conditions, such as: the provision of free spaces between the individual stations (The Institution of Production Engineers 1979, Lotter 1989, Butler 1993, Hollingum 1993, Morach 1988); integrating checking stations in the line (Wick et al 1987, Lotter 1989, Butler 1993, Morach 1988, Astrop 1980, Weimer 1988, Schwartz 1989); careful design of the workpiece carriers (Lotter 1989, Kochan 1990, Rooks 1989); careful integration of any manual workstation required in the system (Lotter 1989, Aronson 1995, Astrop 1980, Seitz 1990, Rooks 1989); minimising the frequency of misfed parts, (Tipping 1969); careful integration of any special processes (such as welding, machining, and adhesive bonding) into the assembly system (Treer 1979, Wick et al 1987, Morach 1988); and, the provision of off-line repair loops for defective assemblies (Astrop 1980, Schwartz 1989).

\subsection{Quick rectification of faults}

Since any breakdowns result in an increase in the assembly costs in dedicated automatic assembly systems, the breakdowns must be rectified quickly. The main sub-conditions are: easy local access to the fault areas line (Boothroyd et al 1982, Lotter 1989, Aronson 1995, Butler 1993); the provision of optical and acoustic signalling of the fault point (Boothroyd et al 1982, Lotter 1989, Butler 1993); the local availability of maintenance personnel at stations with high number of faults (Lotter 1989); implementation of a suitable maintenance strategy to improve the availability of single elements of the system (workheads, feeders, etc.) (Hollingum 1992, Wiendahl et al 1983); and, the provision of a fault recording system which 
keeps a record of the maintenance history of each piece of equipment in the system (Wiendahl 1983).

\subsection{Day to day operation}

This condition is concerned with the human factors in the assembly system, i.e. organizing the personnel activities in the plant to run and maintain the system effectively. Main sub-conditions are: clear definitions of personnel activities and responsibilities (Treer 1979, Lotter 1989, Rooks 1989); organizing the operators to maintain the required quantity of parts in the feeding system (Tipping, 1969, Lotter 1989, Astrop 1980); training the staff about the operation and maintenance of the system (Tipping 1969, Treer 1979, Wick et al 1987, Lotter 1989, Astrop 1980, Rooks 1989); and, providing operators and maintenance staff with all the necessary instructions (Davis 1993).

\subsection{System safety}

Safety measures need to be organised so as to give preference to the following procedural order: personnel, assembly machines, peripheral machinery, and then workpieces and tooling. Many sub-conditions can be included here, such as: the provision of machine safeguards to prevent any access to hazard points in machines during their operation (Wick et al 1987, Aronson 1995, Davis 1993); covering all moving parts which may engage the operator shielding of operators from spray, chip, and broken tools ejection; fail safe movement of parts (in the assembly machine) without injuring the operators; clear display of emergency procedures; the provision of fail-safe interlocks on the assembly machines; guarding the controls to avoid accidental activation of the assembly; easy access (by the operators) to the assembly system emergency stop buttons; application of measures to reduce noise levels to the acceptable permissible limits; and, ensuring that the machines cannot be operated during maintenance (Wick et al 1987).

\section{TECHNICAL AND HUMAN CONDITIONS OF PROGRAMMABLE AUTOMATIC ASSEMBLY SYSTEMS}

The general trend, in the industrial countries, towards the manufacture and assembly of small volumes of different products, with short life-cycle, and high quality has led to the increasing use of programmable assembly (Arnstrom et al 1988). Programmable assembly has many features which satisfy the above requirements. These include the ability to re-program the assembler to accommodate product design changes, the possibility of assembling a different product every shift (providing the changeover time between different batches is short), and the ability to rapidly accommodate various styles of the same product (Boothroyd 1984, Miles 1985). So valuable are these advantages of programmable assembly systems that their higher capital cost can often be justified even for low volumes (Little et al 1993). The programmable assembly decision tree includes eight main conditions. 


\subsection{Design for programmable assembly}

All the design for assembly conditions for dedicated automatic assembly, discussed in the previous section, apply equally to programmable assembly.

\subsection{Technical ability of assembly robots}

The provision of robots with the required technical abilities, to perform the assembly tasks, is the second main condition. Therefore, they should have the ability to do this work, in the required cycle time, and in accordance with all other factors in the assembly process such as the tolerances between the parts, the weight of the parts, and the layout of the assembly workplace (Owen 1984, Rees et al 1987, Lotter 1986, Eshleman et al 1983, Delchambre 1992, Booth et al 1992, Nicholson 1986, Mayer 1988). Other requirements include enough degrees of freedom to perform all the required assembly tasks (Owen 1984, Rees et al 1987, Delchambre 1992); suitable control devices (Owen 1984, Nicholson 1986, Hollingum 1992, Ohashi et al 1994); and the necessary insertion force (Nicholson 1986).

\subsection{Parts presentation and feeding}

This main condition as well as the associated sub-conditions are the same for both dedicated automatic and programmable assembly systems.

\subsection{Efficient control system}

Clearly the sub-conditions in automatic assembly systems are equally applicable here also. An additional sub-condition is: the control system has a decentralised and modular structure to allow for each assembly station to be programmed and debugged independently and to allow for future changes in the assembly system (Aronson 1995, Owen 1984, Mayer 1988, Hollingum 1992).

\subsection{Assembly system architecture}

This condition is about the overall design structure of the assembly system. The main sub-conditions are: providing volume growth flexibility in the system to meet the future demand increases in the assembled products (Hemmingson 1988, Fabricius 1985, Billatos 1988, Aregger 1989); providing design changes flexibility in the system (Owen 1984, Billatos 1988, Andreasen 1986); the use of standard equipment, as much as possible, in building the assembly system (Ohashi et al 1994); application of measures to reduce the changing of grippers required to carry out the assembly operations (Hollingum 1992, Pham et al 1991); and, minimizing the number of programming languages (Mayer 1988).

\subsection{Quick rectification of faults}


The conditions applicable to dedicated assembly systems are equally applicable here. In addition, two other conditions can be included here: ensuring that the robots used in the system are highly reliable (Engelberger 1980); and, the provision of diagnosis aids for the assembly robots (Owen 1984).

\subsection{Education and training}

Proper training, before and after a robotic assembly system installation, is an important factor in the effective use of the system. Almost everybody in the plant will need some sort of training. A training strategy should include: conducting a 'skills assessment' to determine the current level of expertise available in the plant; completing the basic skill training required in the system (Rosato 1986); and, conducting training programmes for all the system staff, to ensure the proper operation and maintenance of the system (Hollingum 1992, Osborne 1986, Singrey 1988, Ziskovsky 1984).

\subsection{System safety}

In addition to the sub-conditions of safety in dedicated assembly systems, the following sub-conditions are included here: shielding solid-state electronic devices (for controlling the robot) from potential radio frequency interference; ensuring the presence of a second person during the execution of any programming or maintenance work; placing a visible amber light near the robot; limited robot speed during teaching and testing of robot programs; and, the provision of an overload protection device on the robot end-effector (Wick et al 1987).

\section{APPLICATION OF THE SYSTEMIZED KNOWLEDGE}

The knowledge has been structured in the form of a decision support system, in which the knowledge is represented as production rules. The conditions (and subconditions) of the knowledge are presented to the user in the form of questions with an appropriate explanation for every question. The possible answers are: (Yes), (No), and (Unknown). The (Unknown) answer leads the user to the lower level subconditions of the main condition.

After extracting the answers to the conditions from the user, the decision support system advises the user about the suitability of the assembly system and the technical and human factors which have not been satisfied. The knowledge has been validated by using two methods: published case studies; and, industrial data. For each type of assembly, the main conditions in the decision tree have been compared with what is actually applied in five published case studies. This comparison has shown a great deal of similarity between the structured knowledge and the actual applications. In the second method, practical industrial data relating to the main conditions and sub-conditions (in the form of questions) have been used. The resulting output from the knowledge based system has demonstrated the validity, suitability and correctness of the structured knowledge.

In one case, the practical data relating to an existing dedicated assembly line was obtained from an industrial company. The data relating to individual 
conditions are summarised in Table 1 . It should be noted that condition C1 corresponds to Section 3.1 of this paper; condition C2 corresponds to Section 3.2 of this paper, and so on. Where the answer to a top level condition is unknown, further questions are asked at the next lower level of the decision tree, for example C2.1, C2.2, to establish whether or not the condition at the previous, higher level is satisfied. Characters $D$ and $E$, next to each condition, indicate whether the particular condition is desirable, or essential.

It can be seen from Table 1 that all the essential conditions have been implemented in the plant. The higher level questions of conditions $\mathrm{C1}, \mathrm{C3}, \mathrm{C4}, \mathrm{C7}$ and C8, have been answered positively. The answers to the higher level questions of conditions $\mathbf{C 2}$ and $\mathbf{C 3}$ were 'Unknown' and therefore their lower level questions have been asked. All the essential sub-conditions of these two main conditions have been answered positively. The sub-conditions of the desirable subcondition C2.3 were also implemented. Therefore, C2 has a positive answer, as all its elements (sub-conditions) have been implemented in the plant. Two desirable sub-conditions of $\mathbf{C 5}$ have positive answers, two have negative answers, and only one with an 'Unknown' answer. The sub-conditions with negative answers are: C5.8

Table 1 Data for a practical automatic assembly system

\begin{tabular}{|lll|}
\hline Conditions & Answers \\
C1 & Applying design for automatic assembly principles (E) & Yes \\
C2 & The provision of efficient and reliable assembly workheads (E) & Unknown \\
C2.1 & Jammed parts can be cleared quickly from the workheads (E) & Yes \\
C2.2 & Workheads fail safe (E) & Yes \\
C2.3 & Ease of maintenance of the workheads (D) & Unknown \\
C2.3.1 & Ease of access to any item which fails regularly (D) & Yes \\
C2.3.2 & Providing spaces between the workheads (D) & Yes \\
C2.3.3 & Providing off the shelf spare parts to the workheads (D) & Yes \\
C3 & Efficient equipment to feed and present the parts (E) & Yes \\
C4 & The provision of an efficient control system (E) & Yes \\
C5 & Careful design of the overall assembly system structure (E) & Unknown \\
C5.1 & Adequate free space between individual stations (E) & Yes \\
C5.2 & Suitable length of the discharge rail (track) (D) & Yes \\
C5.3 & Checking stations are integrated in the line (E) & Yes \\
C5.4 & Avoiding rigid combination of assembly machines (D) & Yes \\
C5.5 & Avoiding rearrangement of preassembled parts (D) & Unknown \\
C5.6 & Careful design for the workpiece carriers (E) & Yes \\
C5.7 & Careful integration of any manual workstations (E) & Yes \\
C5.8 & Attention to the problem of misfed parts (D) & No \\
C5.9 & Careful integration of any special process (E) & Yes \\
C5.10 & The provision of off-line repairs loops (D) & No \\
C6 & Applying precautionary measures to rectify faults quickly (D) & Unknown \\
C6.1 & Easy local access to the fault areas (D) & No \\
C6.2 & Optical and acoustic signalling of the fault point (D) & No \\
C6.3 & Arranging the work point of the maintenance personnel (D) & Unknown \\
C7 & Organizing personnel activities in the plant (E) & Yes \\
C8 & Safety considerations in the system (E) & Yes \\
\hline & & \\
\hline
\end{tabular}


(attention to the problem of misfed parts) and C5.10 (the provision of off-line repair loops). Because all the essential sub-conditions of $\mathbf{C 5}$ have been satisfied, then it is considered to be positively applied in the plant. There is one desirable main condition in the decision support system, and it has not been applied in the plant. It is C6 - applying precautionary measures to rectify faults quickly.

In overall terms, all the essential requirements for the successful implementation of automatic assembly are present. This similarity between the decision support conditions and what is already applied in the plant, is a further evidence of the validity of the systemized knowledge.

\section{CONCLUSION}

The systemized knowledge, in the form of a decision support system, can advise the management about the suitability of a proposed type of assembly system and the steps required for its successful implementation. The management of an existing assembly system can also benefit from the decision support systems by comparing the ideal systems with their actual system. Therefore, the decision support system can advise the management about how to improve any system, and where to concentrate their efforts.

Furthermore, the systemized knowledge can be used as a teaching tool, where the user can be shown a systematic and detailed way of implementing each type of assembly system. In this way, the user can acquire the detailed knowledge about each assembly system, without the need to go through a numerous number of text books and scientific papers.

\section{REFERENCES}

Andreasen, M.M. and T. Ahm (1986), The Relation Between Product Design, Production, Layout and Flexibility, '7th Intr. Conf. on Assembly Automation, Zurich', February, IFS Publications, pp. 161-172.

Aregger, B. (1989), Flexibility Drives Gear Motor Assembly, Assembly Automation, 9(2), pp. 71-74.

Arnstrom, A. and P. Grondahl (1988), An Automatic Small Batch Assembly System Based on the Sub-Batch Principle as Used in the IVF-KTH Concept

Mark II, '9th Intr. Conf. on Assembly Automation', London, March, IFS Publications, pp.63-74.

Aronson, R.B. (1995), Trends in Automated Assembly, Manufacturing Engineering, 115(3), pp. 73-80.

Astrop, A. (1980), Adding a Human Touch to Auto Assembly, Machinery and

Production Engineering, 136(Part 3517), pp. 51-53.

Bailey, J.R. (1986), 'Product Design for Robotic Assembly', in: Automated

Assembly, J.D. Lane (Edt.), Society of Manufacturing Engineers, pp. 104-116.

Billatos, S.B. (1988), An Integrated Analysis of Flexible Assembly Systems, 'Proc. of the Intr. Conf. on Computer Integrated Manufacturing', New York, May,

The Computer Society of the IEEE, pp. 377-382. 
Booth, D.E., M. Khouja and M. Hu (1992), A Robust Multivariate Statistical Procedure for Evaluation and Selection of Industrial Robots, International Journal of Operations and Production Management, 12(2), pp.15-24.

Boothroyd, G. (1984), Use of Robots in Assembly Automation, Annals of the CIRP, 33(2), pp. 475-484.

Boothroyd, G., C. Poli and L. Murch (1982), Automatic Assembly, Marcel Dekker Inc.

Butler, S. (1993), Mechatronic Innovation in Switch Assembly, Assembly Automation, 13(4), pp. 18-20.

Cokayne, A. (1991), The Way of the World, Assembly Automation, 11(4), pp. 29-32.

Coleman, J.R. (1989), Flexible Assembly Flexes Its Muscle, Assembly Engineering, 32(7), pp. 11-14.

Davis, C. (1993), Cost Benefits from Safety Conformance, Assembly Automation, 13(2), pp. 8-10.

Delchambre, A. (1992), Computer-Aided Assembly Planning, Chapman \& Hall.

Engelberger, J.F. (1980), Robotics in Practice, Kogan Page Ltd.

Eshleman, R.L. and F.S. Pagano (1983), What Managers Need to Know When Choosing Robots, National Productivity Review, 2(3), pp.242-256.

Fabricius, F. (1985), An Overview of Flexible Assembly Automation, '6th Intr. Conf. on Assembly Automation', Birmingham, May, IFS Publications, pp.33-40.

Hemmingson, E. (1988), A Universal Concept for Cylinder-Head Assembly, Assembly Automation, 8(2), pp. 77-81.

Holbrook, A.E.K. and P.J. Sackett (1988), Design for Assembly - Guidelines for Product Design, 9th Intr. Conf. on Assembly Automation, London, March, IFS Publications, pp. 201-212.

Hollingum, J. (1992), Automatic Door Latch Assembly at Rockwell, Assembly Automation, 12(4), pp. 12-18.

Hollingum, J. (1993), Modular Delivers úl Million Micro Relay System, Assembly Automation, 13(3), pp. 18-20.

Kochan, A. (1990), Automatic Assembly Improves TRW's Response, Assembly Automation, 10(1), pp. 34-36.

Laszcz, J.F. (1985), Product Design for Robotic and Automatic Assembly, in: International Trends in Manufacturing Technology - Robotic Assembly, K. Rathmill (Edt.), IFS Ltd, pp. 157-172.

Little, D. and A. Hemmings (1993), Scheduling Automated Assembly Systems, Assembly Automation, 13(4), pp. 8-13.

Lotter, B. (1986), Planning and Implementation of Flexible Assembly Cells, '7th Intr. Conf. on Assembly Automation', Zurich, February, IFS Publications, pp.1-9.

Lotter, B. (1989), Manufacturing Assembly Handbook, Butterworths.

Lynch, P.M. (1976), Economic-Technological Modeling and Design Criteria for Programmable Assembly Machines, $\mathrm{PhD}$ Thesis, Massachusetts Institute of Technology.

Mayer, G.E. (1988), Adept's Assembly Automation Programme, '9th Intr. Conf. on Assembly Automation', London, March, IFS Publications, pp. 129-136.

Miles, B.L. (1985), Flexible Assembly Systems, '6th Intr. Conf. on Assembly Automation', Birmingham, May, IFS Publications, pp. 173-178. 
Morach, W. (1988), Flexibility in Automatic Assembly, Industrial and Production Engineering, 12(3), pp. 112-116.

Nicholson, P. (1986), Criteria for Selecting an Assembly Robot, in: Automated Assembly, J. Lane (Edt.), Society of Manufacturing Engineers, pp.295-302.

Ohashi, T., S. Miyakawa and M. Matsunaga (1994), Robots in Mass-Production Automatic Assembly, in: Manufacturing Automation Systems and CIM Factories, K. Asai, S. Takashima and P.R. Edwards (Edts.), Chapman \& Hall, pp. 218-231.

Osborne, D.M. (1986), Training - The Key to Success in the Use of Robots, in: International Trends in Manufacturing Technology - Education and Training in Robotic, T.M. Husband (Edt.), IFS Ltd, pp. 61-67.

Owen, A.E. (1984), Flexible Assembly Systems, Plenum Press.

Pham, D.T. and S.H. Yeo (1991), Strategies for Gripper Design and Selection in Robotic Assembly, International Journal of Production Research, 29(2), pp. 303-316.

Rees, R.J. and C.V. Lloyd (1987), Flexible Automated Assembly, '2nd Intr. Conf. on Computer-Aided Production Engineering', Edinburgh, April, University of Edinburgh, pp. 239-244.

Riley, F.J. (1983), Assembly Automation: A Management Handbook, Industrial Press Inc., New York.

Rooks, B. (1989), Team Effort on Improvement Brings Results and Rewards, Assembly Automation, 9(1), pp. 17-20.

Rosato, P.J. (1986), Training Strategies for Robotic Implementation, in: International Trends in Manufacturing Technology - Education and Training in

Robotics, T.M. Husband (Edt.), IFS Ltd., pp. 69-79.

Schwartz, W.H. (1989), Mechanical Assembly Machines, Systems, and Components, Assembly Engineering, 32(9), pp. 22-32.

Seitz, D. (1990), Job Design in Assembly Automation Systems, Assembly Automation, 10(4), pp. 200-203.

Singrey, R. (1988), Integrating Robots into Automated Systems, Plant Engineering, 42(14), pp. 56-57.

Stoll, H.W. (1986), 'Automation: Teacher and Test for Good Product Design', In: Automated Assembly, J.D. Lane (Edt.), Society of Manufacturing Engineers, pp. 117-129.

The Institution of Production Engineers (1979), A Management Guide to Automated Assembly, London.

Tipping, W.V. (1969), An Introduction to Mechanical Assembly, Business Books Ltd., London.

Treer, K.R. (1979), 'Automated Assembly', Society of Manufacturing Engineers, Michigan.

Warnecke, H.J. (1978), 'Assembly systems now and in future research and development': Annals of the CIRP, 27(2), pp. 597-605.

Weimer, G. (1988), Automatic Assembly Puts it all Together, Automation, 35(11), pp. 15-20.

Wick, C. and R.F. Veilleux (Edts.) (1987), 'Tool and Manufacturing Engineers Handbook, Vol. IV - Quality Control and Assembly', 4th Edition, Society of Manufacturing Engineers (SME). 
Wiendahl, H.P. and W.D. Ziersch (1983), Performance and Personal Bindings in Automated Linked Assembly Lines, '4th Intr. Conf. on Assembly Automation', Japan, October, IFS Publications, pp. 182-197.

Ziskovsky, J.P. (1984), Risk Analysis and the R3 Factor, Robots 8 Conf. Proc.,

Vol. 2 - Future Considerations, Detroit, June, Robotics International of SME, pp. 15:9-15:21

\section{BIOGRAPHY}

Professor Ashok Kochhar is the Lucas Professor of Manufacturing Systems Engineering and the Head of the Department of Mechanical Engineering at the University of Manchester Institute of Science and Technology (UMIST), Manchester, England. His main interests are the Design, Planning and Control of Manufacturing Systems.

Dr Y. Abdul-Hamid is a researcher at the University of Bradford. His main interests are Design of Manufacturing Systems. 